\title{
ANALISA SISTEM INFORMASI KEAMANAN INTERNET SPEEDY PADA PLASA TELKOM TANJUNGBALAI
}

\author{
Khairul Saleh ${ }^{*}$, Tini Fitriani ${ }^{2}$ \\ Universitas Asahan; Jln. Jend. Ahmad Yani, telp/fax (0623)347222 \\ Jurusan Teknik Informatika, Fakultas Teknik UNA, Kisaran Sumatera Utara \\ e-mail: hutasuhutkhairul@gmail.com ${ }^{* 1}$, tinifitriani1212@ gmail.com²
}

\begin{abstract}
Abstrak - Penerapan teknologi informasi pada saat ini sangat erat kaitannya dalam kehidupan seharihari. Komunikas yang pada mulanya hanya disampaikan dengan cara yang sangat sederhana yakni secara "mouth by mouth" (mendatangi secara langsung antara manusia yang satu dengan manusia yang lain). Selain itu, sistem keamanan jaringan internet speedy juga digunakan sebagai proses untuk mencegah dan mengidentifikasi pengguna yang tidak sah(penyusup) dari jaringan internet. Tujuannya adalah untuk mengantisipasi resiko jaringan internet yang dapat berupa ancaman fisik maupun logik. Yang dimaksud dengan ancaman fisik itu adalah yang dapat merusak bagian fisik computer atau hardware computer sedangkan ancaman logic yaitu berupa pencurian data atau penyusup yang membobol akun seseorang.
\end{abstract}

Kata Kunci : Sistem Keamanan, Jaringan Speedy

Abstract - Application of information technology at this time is very closely related in everyday life. Komunikas which at first only delivered in a very simple way that is "mouth by mouth" (come directly between one human with another human). In addition, internet speedy network security system is also used as a process to prevent and identify unauthorized users (intruders) from the Internet network. The goal is to anticipate internet network risks that can be physical or logical threats. What is meant by physical threats is that can damage the physical part of the computer or hardware computer while the threat of logic in the form of data theft or intruders who break into someone's account.

Keywords : Security System, Speedy Network

\section{PENDAHULUAN}

Penerapan teknologi informasi pada saat ini sangat erat kaitannya dalam kehidupan sehari-hari. Komunikas yang pada mulanya hanya disampaikan dengan cara yang sangat sederhana yakni secara "mouth by mouth" (mendatangi secara langsung antara manusia yang satu dengan manusia yang lain). Tetapi ketika jarak yang harus ditempuh terasa cukup jauh, maka mulai terjadi kendala sehubungan hal tersebut. Teknologi yang canggih ini banyak disalahgunakan oleh Hacker yang mencoba mengambil keuntungan dengan cara meretas sistem keamanan jaringan internet untuk keuntungan mereka sendiri. Dengan bahasa-bahasa pemrograman dan trik yang jarang diketahui oleh orang awam mereka mencoba mengambil keuntungan dari sisi kelemahan keamanan internet speedy tersebut.Selain itu, sistem keamanan jaringan internet speedy adalah proses untuk mencegah dan mengidentifikasi pengguna yang tidak sah(penyusup) dari jaringan internet.

\section{TUJUAN}

Tujuannya adalah untuk mengantisipasi resiko jaringan internet yang dapat berupa ancaman fisik maupun logik. Yang dimaksud dengan ancaman fisik itu adalah yang dapat merusak bagian fisik computer atau hardware computer sedangkan ancaman logic yaitu berupa pencurian data atau penyusup yang membobol akun seseorang. 
Tujuan Internal

Untuk membantu menyelesaikan permasalahan terkait sistem keamanan internet speedy pada PT. Telkom Indonesia Plasa Tanjungbalai.

Tujuan Eksternal

Bagi penulis

Untuk menambah wawasan dan pengalaman tentang situasi dan masalah yang di hadapi dalam dunia kerja terutama pada PT. Telkom Indonesia Plasa Tanjungbalai.

\section{Bagi pembaca}

Untuk memberitahu pembaca bagaimana sistem keamanan internet speedy yang digunakan dan dapat mengetahui apa saja yang diperlukan pada saat melakukan setting keamanan internet speedy di PT. Telkom Indonesia Plasa Tanjungbalai.

\section{METODE PENELITIAN}

Teknik pengumpulan data yang dilakukan penulis adalah bertujuan untuk mengumpulkan berbagai informasi yang dibutuhkan untuk menyelesaikan penelitian terkait Sistem Keamanan Internet Speedy di PT. Telkom Indonesia Plasa Tanjungbalai.

1. Metode Wawancara ( Interview )

Menanyakan secara langsung pada narasumber terkait Sistem Administrasi pasang baru Indihome di PT. Telkom Indonesia Plasa Tanjungbalai.

2. Studi Literatur

Mengumpulkan data dengan membaca dan mempelajari bukubuku atau mencari sumber lainnya yang berkaitan dengan objek yang di teliti di PT. Telkom Indonesia Plasa Tanjungbalai.

\section{HASIL DAN PEMBAHASAN}

3.1 Analisis Sistem Berjalan

Analisis sistem berjalan yaitu menganalisis sistem keamanan internet speedy di PT. TELKOM INDONESIA Plasa Tanjungbalai.

Speedy adalah penyelenggara jasa Internet yang dimiliki oleh Telkom Indonesia. Speedy berbasis teknologi akses asymmetric digital subscriber line (ADSL) dan gigabit passive optical network (GPON) dengan menggunakan jaringan fiber optik sampai ke rumah atau Fiber to the home (FTTH).

Bagi pelanggan ADSL Modem ( misalnya : Telkom Speedy ), banyak yang tidak mengerti tentang keamanan account.Sehingga tidak merasa kalau setting-an default modem ADSL sangatlah rawan, sangat mudah bagi yang mau mengganggu / merusak koneksi internet meraka, diantara kekurangan setting keamanannya adalah:

a. Teknisi telkom speedy hanya men-set Modem ADSL secara default , sehingga mudah ditebak username dan password dari modem ADSLnya.Misalnya : username : admin password: admin , padahal dengan mengetahui username dan password seseorang bisa meng-otakatik settingan modem ADSL tersebut.

b. Setiap Pelanggan Telkom speedy diberi satu IP public ,artinya : dengan menggunakan IP public tersebut, seseorang bisa mengakses Modem ADSL tersebut dari manapun selama ada koneksi internet.Jadi untuk seseorang yang mengetahui IP public tersebut, dia bisa men-setting modem ADSL dari manapun. Caranya? ( harap untuk menambah ilmu pengetahuan / bukan untuk merusak dan mengganggu. 


\subsubsection{Analisa Sistem Berjalan}

Analisis prosedur yang berjalan yaitu kegiatan atau alur kerja dan dokumen dari suatu sistem.

3.1.1.1 Use Case Diagram
Use Case Diagram untuk sistem keamanan internet speedy di PT. TELKOM INDONESIA Plasa Tanjungbalai.

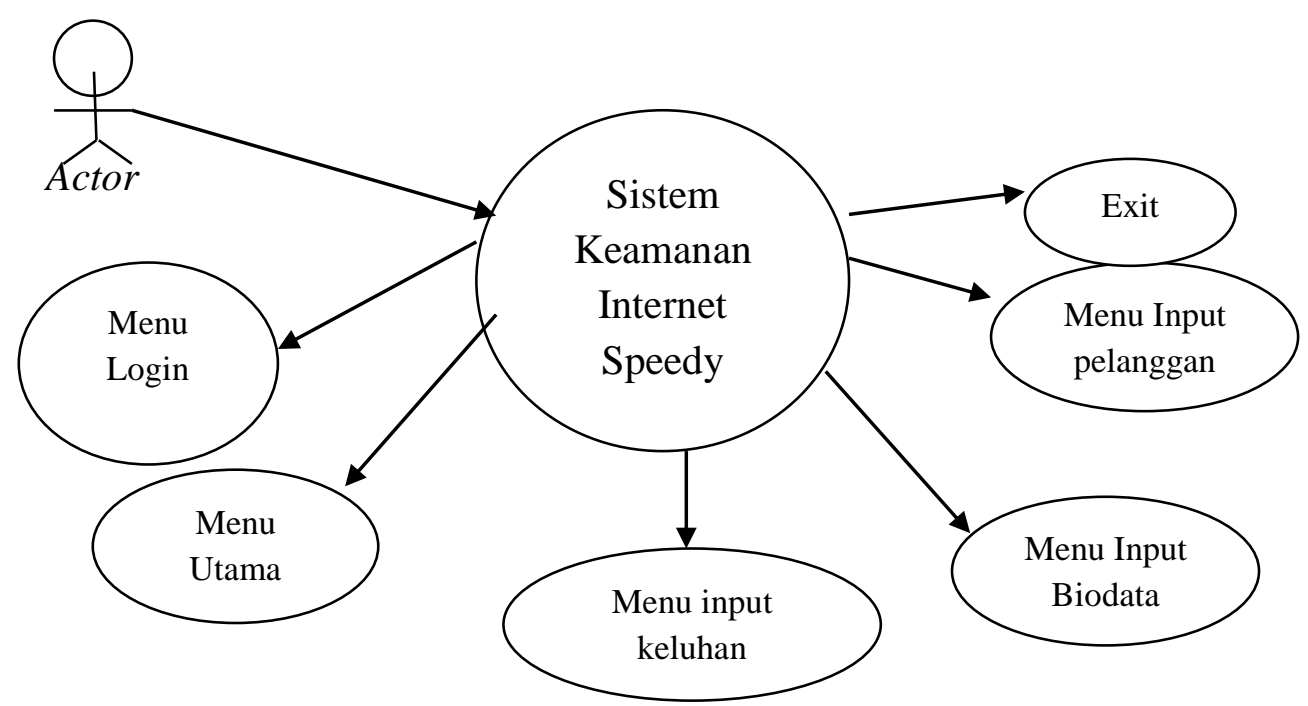

Gambar 4.1 Use Case Diagram

\subsubsection{Squence Diagram}

Squence Diagram untuk sistem keamanan internet speedy di PT. TELKOM INDONESIA Plasa Tanjungbalai.

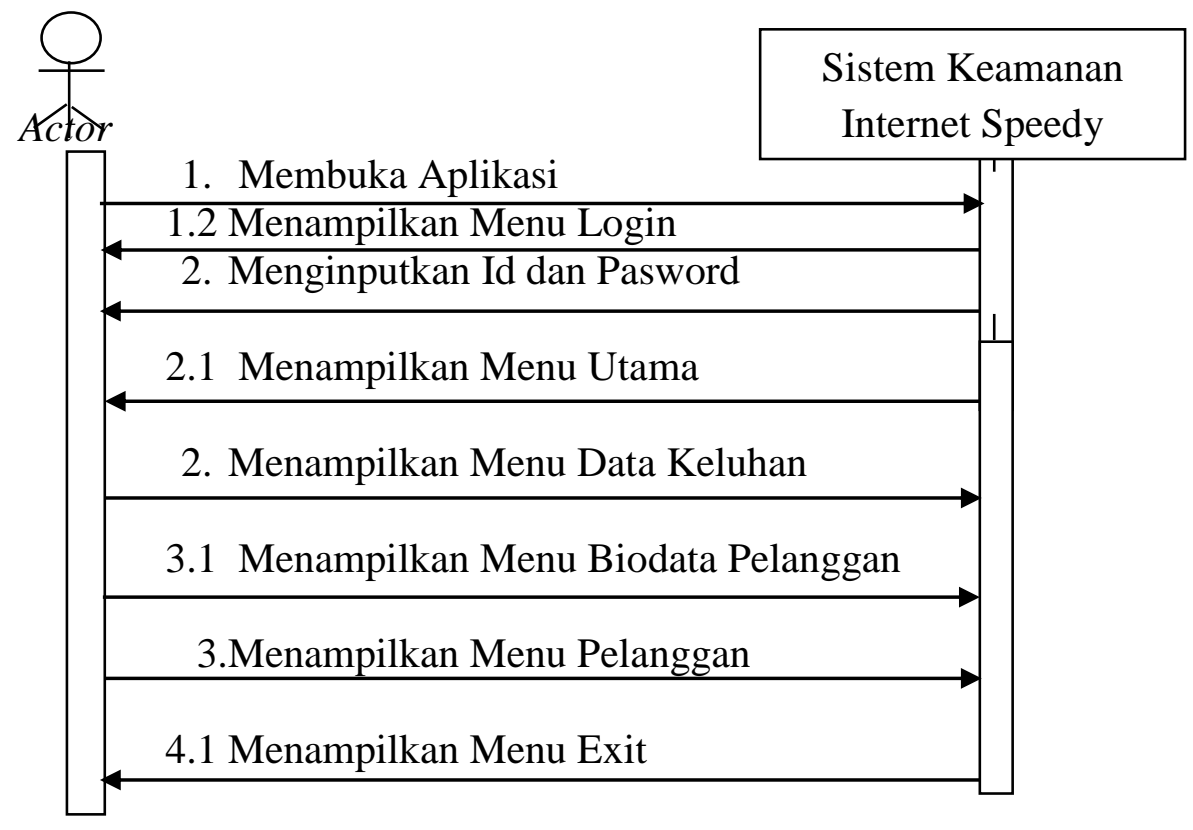

Gambar 4.3 Squence Diagram 


\subsubsection{Activity Diagram}

Activity Diagram untuk sistem keamanan internet speedy di PT. TELKOM INDONESIA Plasa Tanjungbalai.

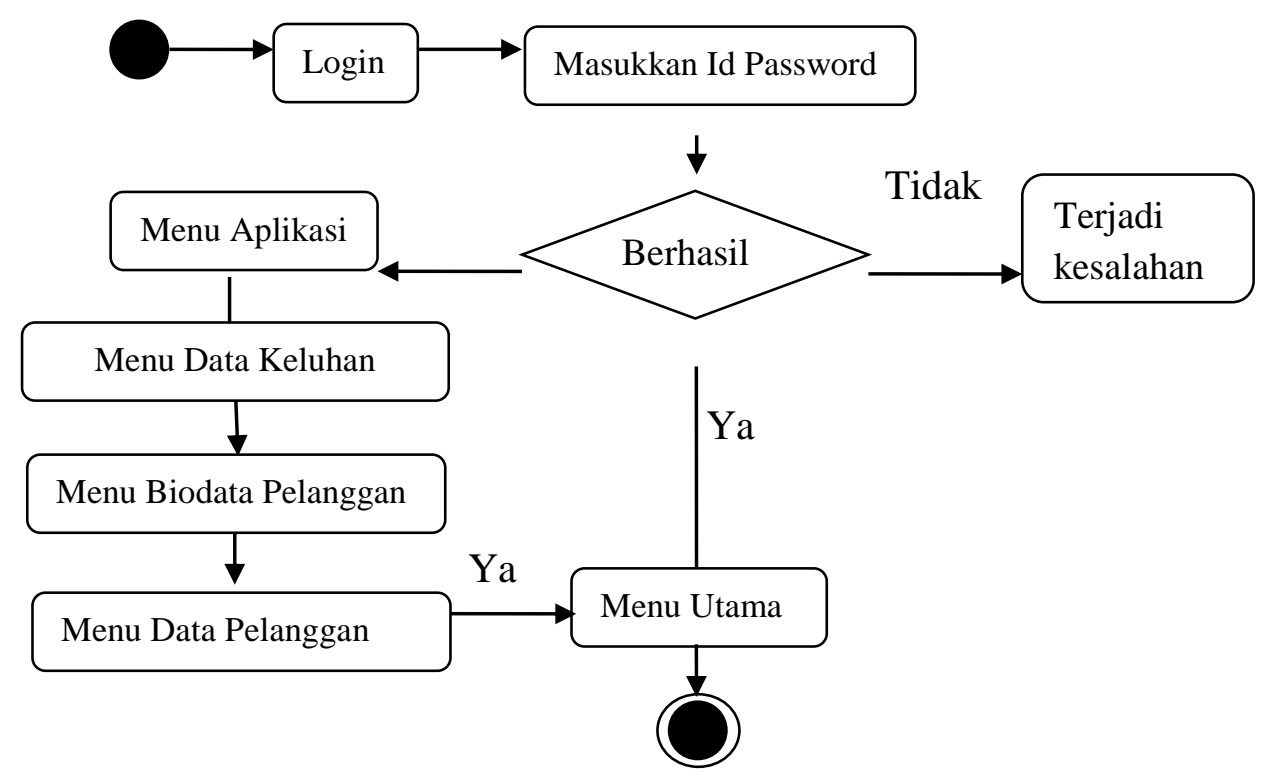

Gambar 4.4 Activity Diagram

3.2 Analisis Sistem Perancangan pada Aplikasi Yang Berjalan

Perancangan menentukan bagaimana suatu sistem akan menyelesaikan apa yang mesti diselesaikan. Tahap ini menyangkut mengkonfigurasi dari komponenkomponen perangkat lunak dan perangkat keras dari suatu system sehingga setelah instalasi dari sistem akan benar-benar memuaskan rancangan bangun yang telah ditetapkan pada akhir tahap analisa sistem, (Jogianto H.M : 2001). Adapun bebrapa rancangan aplikasi yaitu sebagai berikut :

\subsubsection{Tampilan Menu Login Microsoft visual studio \\ Adapun tampilan menu login \\ pada aplikasi Microsoft visual studio tentang Sistem Keamanan Internet Speedy Pada Plsa Telkom Tanjungbalai yaitu sebagai berikut .}




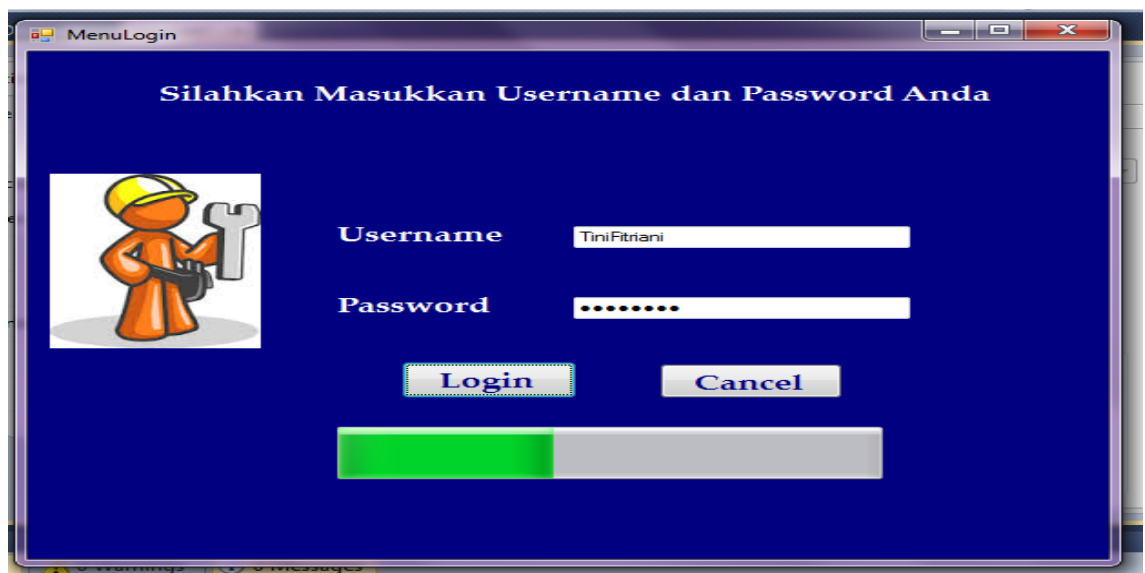

Gambar : 4.13 Tampilan Menu LoginMicrosoft visual studio

\subsubsection{Tampilan Menu Utama Microsoft visual studio}

Adapun tampilan menu utama aplikasi Microsoft visual studio tentang Sistem Keamanan Internet Speedy Pada Plsa Telkom Tanjungbalai yaitu sebagai berikut :

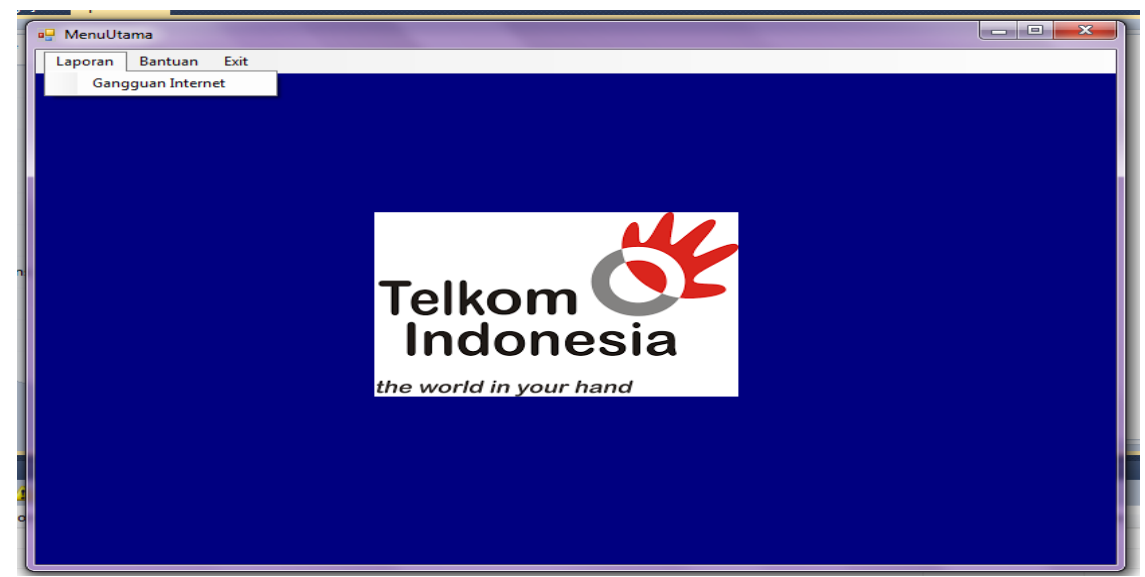

Gambar : 4.14 Tampilan Menu UtamaMicrosoft visual studio

\subsubsection{Tampilan Menu Laporan Gangguan Internet Microsoft visual studio}

Adapun tampilan menu laporan gangguan internet pada aplikasi Microsoft visual studio tentang Sistem Keamanan Internet Speedy Pada Plsa Telkom Tanjungbalai yaitu sebagai berikut : 


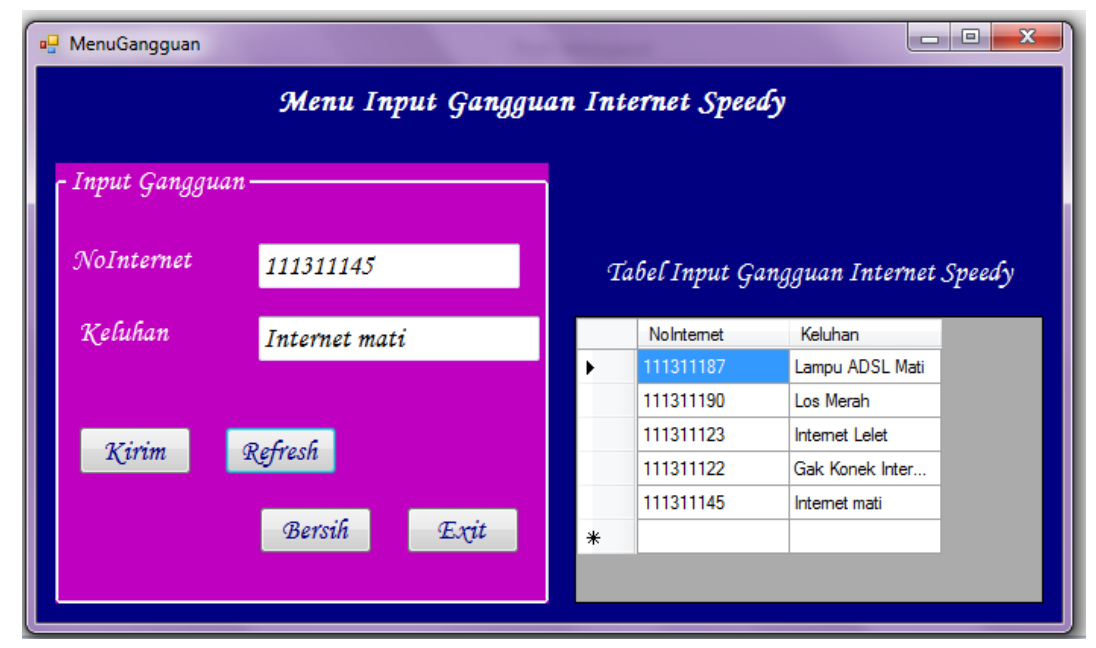

Gambar : 4.15 Tampilan Menu Gangguan Internet Microsoft visual studio

\subsubsection{Tampilan Menu Biodata Pelanggan Microsoft visual studio}

Adapun tampilan menu biodata pelanggan pada aplikasi Microsoft visual studio tentang Sistem Keamanan Internet Speedy Pada Plsa Telkom Tanjungbalai yaitu sebagai berikut :

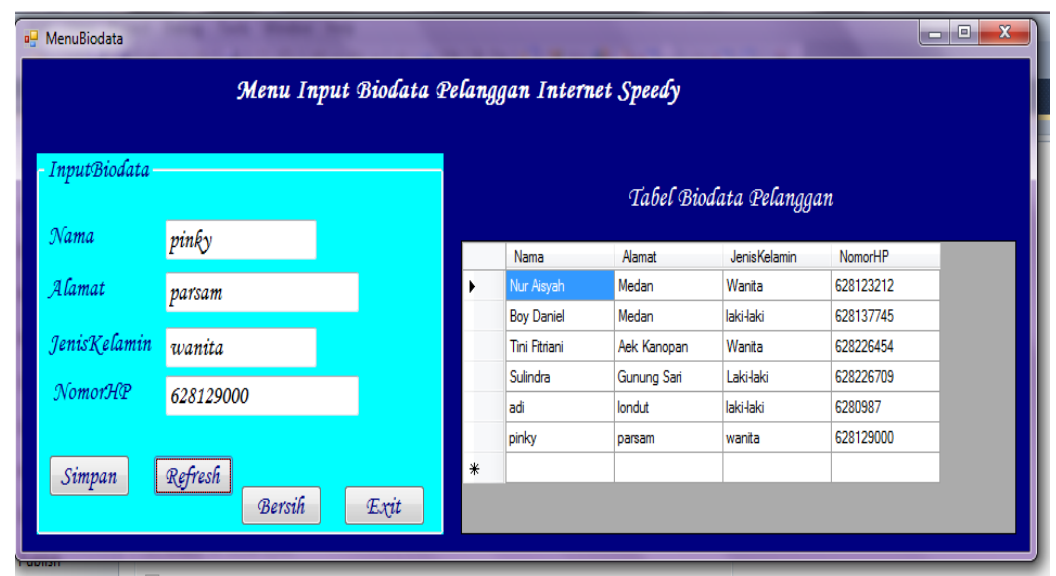

Gambar : 4.16 Tampilan Menu Data Pelanggan Microsoft visual studio

\subsubsection{Tampilan Menu Pelanggan Microsoft visual studio}

Adapun tampilan menu Pelanggan pada aplikasi Microsoft visual studio tentang Sistem Keamanan Internet Speedy Pada Plsa Telkom Tanjungbalai yaitu sebagai berikut: 


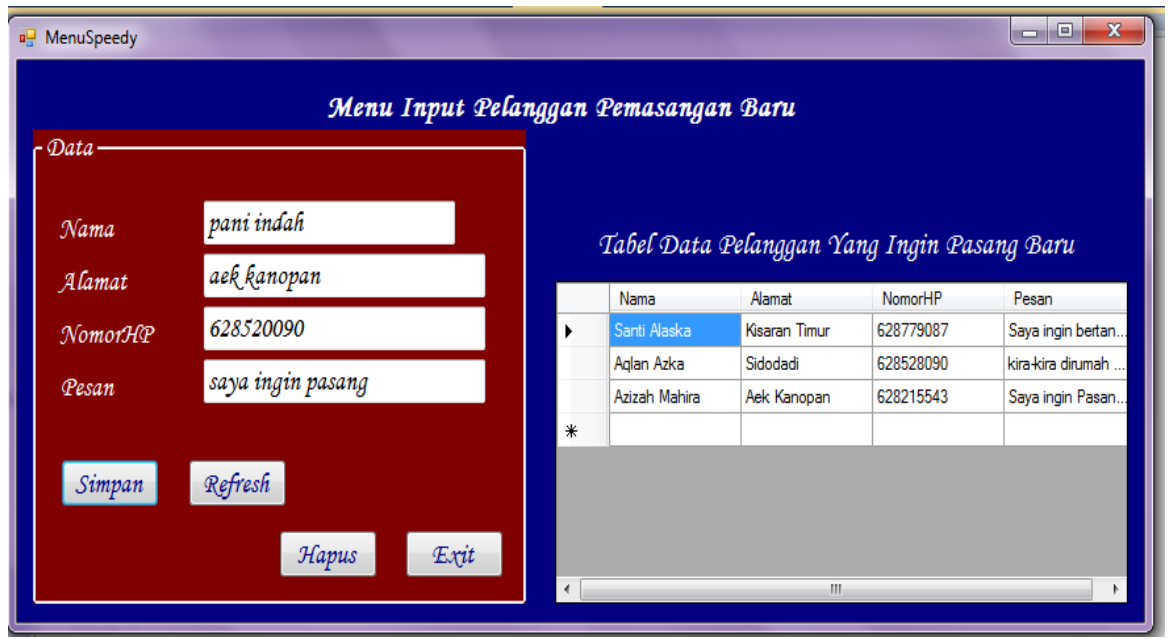

Gambar : 4.16 Tampilan Menu Pelanggan Microsoft visual studio

\subsubsection{Tampilan Menu Exit Microsoft visual studio}

Adapun tampilan menu exit pada aplikasi Microsoft visual studio tentang Sistem Keamanan Internet Speedy Pada Plsa Telkom Tanjungbalai yaitu sebagai berikut :

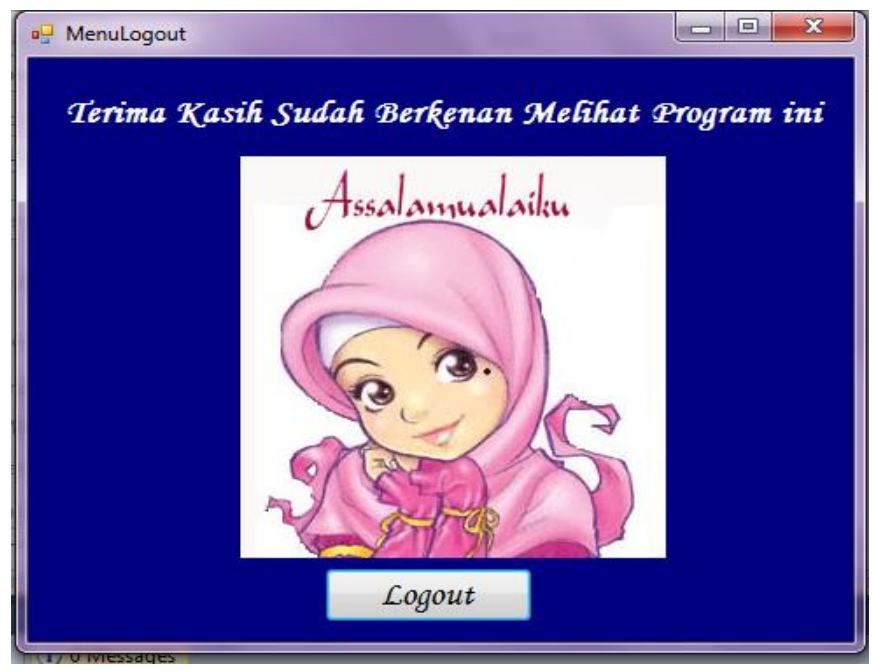

Gambar : 4.17 Tampilan Menu Exit Microsoft visual studio

\section{KESIMPULAN}

Dari uraian diatas penyusun dapat memberikan beberapa kesimpulan yang dapat diambil dari laporan ini yaitu sebagai berikut :
1. Sistem informasi merupakan suatu perkumpulan data yang terorganisasi beserta tatacara penggunaanya yang mencangkup lebih jauh dari pada sekedar penyajian. Istilah tersebut menyiratkan suatu maksud yang ingin dicapai dengan jalan memilih dan 
mengatur data serta menyusun tatacara penggunaanya.

2. Selain itu, sistem keamanan jaringan internet speedy juga digunakan sebagai proses untuk mencegah dan mengidentifikasi pengguna yang tidak sah(penyusup) dari jaringan internet.

3. Tujuannya adalah untuk mengantisipasi resiko jaringan internet yang dapat berupa ancaman fisik maupun logik. Yang dimaksud dengan ancaman fisik itu adalah yang dapat merusak bagian fisik computer atau hardware computer sedangkan ancaman logic yaitu berupa pencurian data atau penyusup yang membobol akun seseorang.

\section{SARAN}

Dalam Penulisan Laporan kali ini penyusun sangat menyadari masih banyak terdapat kekurangan. Oleh sebab itu, kritik dan saran konstruktif dari pembaca sangat penyusun harapkan demi perbaikan dimasa yang akan datang.

\section{DAFTAR PUSTAKA}

[1] Jogiyanto HM. 2005. Pengenalan Komputer : Dasar Ilmu Komputer, Pemrograman, Sistem Informasi. Yogyakarta: Penerbit ANDI.

[2] Kisworo, Budi H, 2009, Buku Pedoman Praktek Kerja Lapangan (Magang) dan Tugas Akhir, STAIN Curup, Bengkulu.

[3] Nugroho, A., (2005), “Analisis dan Perancangan Sistem Informasi Dengan Metodologi Berorientasi Objek", Penerbit Informatka, Bandung.

[4] Sutanta, E.,2004.Sistem Informasi. Yogyakarta: Penerbit Graha Ilmu.

[5] Anonymous. 2010. Sejarah Internet dan Perkembangan Internet. http://www.sejarahinternet.com/sejarah-internet/
[6] https://id.wikipedia.org/wiki/Visual_ Basic_NET

[7] http://elib.unikom.ac.id/files/disk1/39 3/jbptunikompp-gdl-anggaradit19638-3-bab2.pdf.

[8] https://novikaginanto.wordpress.com/ photo/pengertian-speedy/

[9] https://id.scribd.com/doc/142145086/ Definisi-Dan-Pengertian-InternetMenurut-Para-Ahli

[10] http://rayendar.blogspot.co.id/201 5/06/analisis-data-menurut-sugiyono2013.html. 